IP Periodica Polytechnica Chemical Engineering

62(1), pp. 8-20, 2018

https://doi.org/10.3311/PPch.11148

Creative Commons Attribution (i)

RESEARCH ARTICLE

\section{Structure, Mechanical and}

Electrochemical Properties of

Thermally Reduced Graphene

Oxide-poly (Vinyl Alcohol) Foams

\author{
Wenxiu Wang ${ }^{1}$, Hui Xu ${ }^{1}$, Jian Chen ${ }^{1 *}$, Yuanfang Shen ${ }^{1}$, Imre Bertóti ${ }^{2}$, \\ Xinli Guo ${ }^{1 * *}$, Xiangru Shi ${ }^{1}$, Zuhair Agab Elsiddig ${ }^{1,3}$
}

Received 16 June 2017; accepted after revision 03 September 2017

\begin{abstract}
Graphene oxide foams with a wide range of poly (vinyl alcohol) contents were synthesized by freeze casting, and then thermally reduced at $300^{\circ} \mathrm{C}$ in argon atmosphere. Their thermal stability, microstructure, composition and chemical states of constituents, mechanical and electrical properties were investigated by X-ray diffraction, scanning electron microscopy, X-ray photoelectron spectroscopy, thermogravimetry, compressive testing and electrochemical analysis. The results indicated that the PVA content highly influenced the crystallinity and microstructure, resulting in different mechanical properties. After thermal reduction, not only graphene oxide was reduced to graphene, but also PVA was subjected to partial pyrolysis. With the increase of the PVA content, the intensity of the sp2 $C-C$ bond decreased while the sp3 $C$-C bond increased. Although the mechanical properties decreased after thermal reduction, the composite foams still showed high cyclic structure stability up to $18 \%$ compression strain. Meanwhile, the reduced foams exhibited high electrical conductivity. Applying as anodes in lithium ion battery, the initial discharge capacity for the foams can reach $1822 \mathrm{~mA} \mathrm{~h} \mathrm{~g}^{-1}$ and

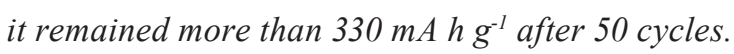

\section{Keywords}

graphene, PVA, thermal reduction, mechanical properties

\footnotetext{
${ }^{1}$ School of Materials Science and Engineering,

Jiangsu Key Laboratory of Advanced Metallic Materials,

Southeast University, Jiangning District, Nanjing 211189, China

${ }^{2}$ Institute of Materials and Environmental Chemistry,

Research Centre for Natural Sciences, Hungarian Academy of Sciences,

Budapest H-1519, Hungary

${ }^{3}$ School of Mechanical Engineering, School of Mechanical Engineering,

Karary University, Khartoum, 12304, Sudan

*First corresponding author, e-mail: j.chen@seu.edu.cn

*Second corresponding author, e-mail: guo.xinli@seu.edu.cn
}

\section{Introduction}

Graphene, a single sheet of carbon atoms patterned in a hexagonal lattice form, has recently attracted much attention for its excellent mechanical, electronic and thermal properties [1, 2]. Self-assembly of graphene is a simple method for the preparation of novel materials, such as one-dimensional (1D) tube-in-tube nanostructures [3], and two-dimensional (2D) films [4, 5]. It is believed that three dimension (3D) graphene architecture, similar to a foam, will further expand its significance in various applications $[6,7]$, such as electronic devices including supercapacitor, lithium-ion batteries, fuel cells, dye-sensitized solar cells, electrochemical sensors, environmental clean-up and biomedical equipments [8-10]. For example, 3D graphene architecture with different pore sizes from sub-micrometre to several micrometres was obtained by Kim et al. [11] and exhibited excellent electrochemical performance due to the high-rate transportation network of the electrolyte ions and multidimensional electron transport pathways for a high performance field emitter.

Notwithstanding the great potentials of graphene foams, there is a major concern on the structure stability, which can strongly affect the reliability and performance of this material. To achieve the better structure stability, polymeric materials such as Poly (vinyl alcohol) (PVA) can be blended with graphene or graphene oxide (the precursor for graphene) due to the strong bonding between them. It has been found that not only the mechanical properties but also electrochemical properties of the composites can be well improved [12, 13].

Generally the composites can be divided into three categories in term of the relative content ratio of graphene and polymer. Firstly, the graphene (GR) or graphene oxide (GO) is the matrix, and a limited amount of PVA usually less than $10 \mathrm{wt} . \%$ were added to improve the stacking of carbon planes [14-17]. For example, Chen et al. [18] added $10 \mathrm{wt} \% \%$ PVA to form a stable network in which PVA chains align along the GO plane to prevent the restacking of GO nanosheets in the drying process and thus equipped with high capacity and excellent rate performance as anode materials for Li-ion batteries after reduction. On the other hand, GR or GO nanosheets can be added into the PVA matrix in order to obtain better mechanical, 
thermal and electrical properties [19-22]. The amount of GR or GO is usually low ( $<10 \mathrm{wt} . \%)$ to avoid the aggregation [23]. Zhang et al. [24] added 0.8 wt.\% GO into a PVA matrix and the resulting GO/PVA hydrogel exhibited a $132 \%$ increase in tensile strength. Ye et al. [25] fabricated 3D GO-epoxy composite aerogel with maximum 9 wt.\% GO, which not only exhibits a higher decomposition temperature and better mechanical strength $(\sim 0.23 \mathrm{MPa})$, but also achieves high elasticity, as it recovers from a large compressive strain without significant permanent deformation.

Besides the composites based on GO or PVA matrix mentioned above, several researchers [26, 27] indicated that $\mathrm{GO}$ / PVA foams with comparable weights of GO and PVA were also obtained using solution mixture and freeze casting as GO and PVA are hydrophilic and can be well dispersed in water. Bai et al. [28] fabricated the GO/PVA nanocomposite hydrogel with various weight ratios $\left(\mathrm{r}_{\mathrm{P} / \mathrm{G}}\right)$ from 1:1 to $1: 40$. It was found that GO sheets formed a network and PVA acted as a cross-linking agent and the GO/PVA hydrogel can be used for selectively releasing drugs. Kim et al. [29] explored the gelation of aqueous dispersions composed of GO and PVA with $\mathrm{r}_{\mathrm{P} / \mathrm{G}}$ in the range of $3: 1$ to $1: 15$ and found that the compression mechanical properties of GO aerogels prepared by freeze casting were strongly affected by their weight ratios. The material with $r_{\mathrm{P} / \mathrm{G}}=1: 2$ can fully recover without fracture even after $94 \%$ compression.

All the researches indicated that the composite foams can exhibit improved properties, however, the effects of PVA content were not investigated deeply. It is of interest to find whether there is any transition from GO network to PVA network with the change of weight ratio? Does the 3D structure and the related structure stability affected? These questions are of both scientific and technical importance in building up designed foams for further applications.

A number of studies indicated that GR foams can be used in Li-ion batteries and supercapacitors [14, 30-32], which can be obtained by the reduction of GO foams using chemical reduction and thermal reduction. For example, Chen et al. [19] reduced GO foams by mild chemical reduction at $95{ }^{\circ} \mathrm{C}$ under atmospheric pressure using $\mathrm{NaHSO}_{3}, \mathrm{Na}_{2} \mathrm{~S}$, Vitamin $\mathrm{C}$, $\mathrm{HI}$, and hydroquinone and proved their potential applications in supercapacitors. However, the recovered conductivity by chemical route was usually less than that obtained by thermal reduction [7]. It makes sense that the electrical conductivity of GO/PVA composites could be recovered by thermal reduction as not only GO can be reduced but also PVA can be carbonized at high temperature. The chemical composition and bonding, the structure stability of the reduced GO/PVA (r-GO/PVA) can also be significantly affected by the thermal reduction.

Therefore, in this work 3D architectures of pure $\mathrm{GO}$ and $\mathrm{GO} /$ PVA composites with different weight ratios (GO: $\mathrm{PVA}=3: 0.5$ to $3: 5)$ were synthesized by solution mixture and freeze casting. With post thermal treatment, their phase, composition and element states of constituents, pore structure, mechanical properties and electrochemical performance in lithium ion batteries were investigated.

\section{Experimental \\ 2.1 Materials}

Graphene oxide (GO) was synthesized using a modified Hummers method [33] using natural graphite powders ( $\sim 200 \mathrm{~mm})$ The obtained GO solution was exfoliated by ultrasonication for half an hour prior to further use.

To prepare the GO/PVA suspension, a certain amount of PVA powder (1788, MW=22,000, Aladdin) was slowly dissolved in deionized water at $85^{\circ} \mathrm{C}$ for 20 mins. GO solution $(17 \mathrm{mg} / \mathrm{ml})$ was added in the PVA solution and kept stirring at $85^{\circ} \mathrm{C}$ for 40 mins. The weight ratio of $\mathrm{GO}$ and PVA $\left(\mathrm{r}_{\mathrm{GO} / \mathrm{PVA}}\right)$ was set to $3: 0.5,3: 1,3: 2,3: 3$ and $3: 5$.

The mixture was then placed in a polydimethylsiloxane (PDMS) mould with a diameter of $12 \mathrm{~mm}$ and a height of $15 \mathrm{~mm}$ as shown in Fig. 1. When the aqueous solution was fully frozen by liquid nitrogen from the top, the frozen samples (Fig. 1b) were taken out from the mould and dried for $48 \mathrm{~h}$ at $-50^{\circ} \mathrm{C}$. For thermal treatment, the foams were heated in Ar atmosphere to $300{ }^{\circ} \mathrm{C}$, and then kept for $2 \mathrm{~h}$, Finally, the samples were cooled with the furnace. In comparison, starting/original GO and thermally reduced GO (r-GO) samples were also prepared.

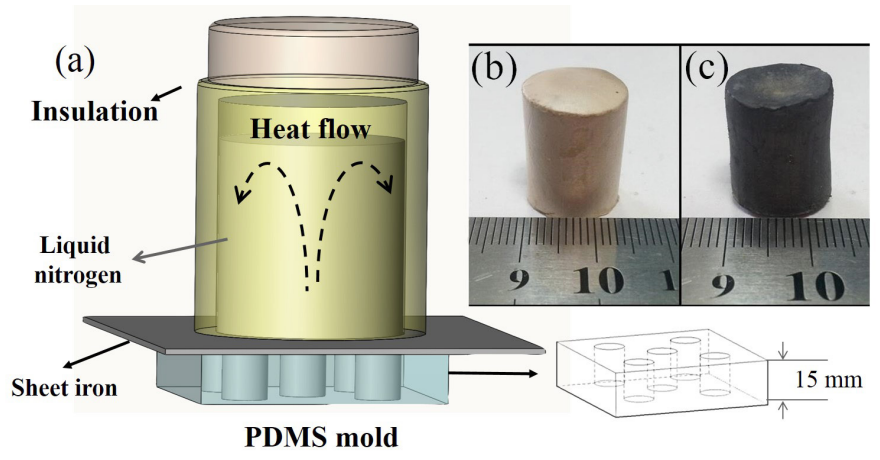

Fig. 1 (a) The schematic diagram of freeze drying, and typical photos of (b) GO/PVA foam (c) thermally reduced r-GO/PVA foam.

\subsection{Characterization}

Thermal stability analysis of the foams were conducted on a thermogravimetric analyser (TGA) (Perkin-Elmer TGA2050) from 50 to $800^{\circ} \mathrm{C}$ at $10^{\circ} \mathrm{C} \cdot \mathrm{min}^{-1}$ heating rates in $\mathrm{N}_{2}$ atmosphere. The X-ray diffraction (XRD) analysis was performed on a Rigaku SmartLab TM 3 kW diffractometer with $\mathrm{Cu} \mathrm{K} \alpha$ radiation $(\lambda=1.54 \AA)$ at a scanning speed of $5^{\circ} \cdot \mathrm{min}^{-1}$ from $5^{\circ}$ to $90^{\circ}$. Raman spectroscopy was carried out on a Horiba Jobin Yvon LabRAM HR800 Micro-Raman spectroscope with excitation laser beam wave-length of $532 \mathrm{~nm}$. To investigate the microstructure, the foam was cut into a cylinder with height $\sim 1 \mathrm{~cm}$ and then investigated using scanning electron microscopy (SEM) (FEI Sirion-200 field emission scanning electron microscope). 
For the composition and chemical state analysis the heat treated monoliths were crushed and pieces of about $3 \times 3 \times 1 \mathrm{~mm}$ were selected from the inner part of all samples. X-ray photoelectron spectra were recorded on a Kratos AXIS Ultra DLD spectrometer operated at fixed analyser transmission mode, using monochromatic $\mathrm{Al} \mathrm{Ka} \mathrm{K}_{1,2}$ excitation. Photoelectron lines of the main constituent elements, i.e., the C1s and O1s were acquired by $0.1 \mathrm{eV}$ steps. Spectra were referenced to the energy of the $\mathrm{C} 1 \mathrm{~s}$ line of the sp2 type graphitic carbon, set at $284.3 \pm 0.1 \mathrm{eV}$ binding energy or to the energy position of $\mathrm{sp} 3$ carbon set at $284.9 \pm 0.1 \mathrm{eV}$ in cases where this was the predominant C1s peak. Spectra were acquired and processed by the Kratos Vision software package. Area intensity data were obtained after Shirley type background removal. Quantitative analysis was performed by the XPS MultiQuant program [34].

\subsection{Mechanical measurements}

Compression tests were performed by a Compression Testing Machine (IBTC-300, Care-mc Co., China). All materials including GO/PVA and r-GO/PVA foams were compressed using a displacement-controlled mode with a ramp rate of $2 \mathrm{~mm} \cdot \mathrm{min}^{-1}$ to $50 \%$ strain.

For the r-GO/PVA foams, the simultaneous mechanical-electrical behaviour was carried out during single and cyclic compression testing by the adoption of a DC power supply (M8811, Maynuo Co., China). 50 cycles under a compression rate of $2 \mathrm{~mm} \cdot \mathrm{min}^{-1}$ to $\sim 15 \%$ strain were used.

\subsection{Electrochemical measurements}

The electrochemical properties of the samples were determined using a 2032-type coin-cell format. The electrode was cut from the as-prepared sample which remained the original 3D structure. Pure lithium foil and a micro-porous polypropylene film (Liyuan lidian, China) were used as the counter-electrode and separator, respectively. The electrolyte consisted of a solution of $1 \mathrm{M} \mathrm{LiPF}_{6}$ in ethylene carbonate (EC)/ dimethyl carbonate (DMC) (1:1 by volume). The cells were assembled in an argon-filled glove box with the concentrations of moisture and oxygen below $1 \mathrm{ppm}$. Cyclic voltammetry $(\mathrm{CV})$ measurements were performed by the electrochemical station (CHI660E, $\mathrm{CH}$ instruments, China) with a scan rate of $0.5 \mathrm{mV} \cdot \mathrm{s}^{-1}$.

\section{Results and discussion \\ 3.1 Thermal stability}

The thermal stability of GO, PVA and the GO/PVA foams is shown in Fig. 2. For the GO, the mass decreases slightly when the temperature increases to $\sim 110^{\circ} \mathrm{C}$ due to the loss of adsorbed water. A sharp drop is observed between $150{ }^{\circ} \mathrm{C}$ and $250{ }^{\circ} \mathrm{C}$ which can be ascribed to the decomposition of labile oxygen functional groups. [35] With the increase of temperature, the mass is decreased gradually up to $800{ }^{\circ} \mathrm{C}$.

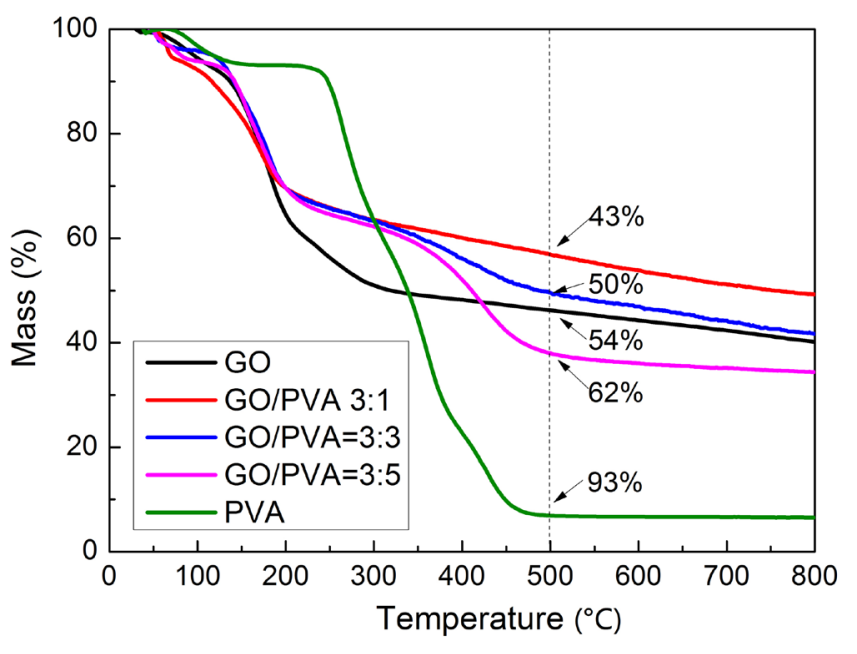

Fig. 2 TGA results of GO, PVA and GO/PVA composite foams.

The PVA showed better thermal stability than GO from room temperature up to $\sim 250{ }^{\circ} \mathrm{C}$. The initial mass loss below $150^{\circ} \mathrm{C}$ can be also attributed to the removal of absorbed water. The dissociation of the hydroxyl bonds, and other decomposition processes gained high velocity above $250{ }^{\circ} \mathrm{C}$ and ceased down above $450{ }^{\circ} \mathrm{C}$. [36] The total mass loss of PVA at $500{ }^{\circ} \mathrm{C}$ is $\sim 93 \%$. As the original $\mathrm{C}$ content in PVA $\left(\left[\mathrm{C}_{2} \mathrm{H}_{4} \mathrm{O}\right]_{n}\right)$ is $55 \mathrm{wt} . \%$, the loss can be caused not only by the loss of $\mathrm{H}$ and $\mathrm{O}$, but also of $\mathrm{C}$ through the formation of carbon-containing gases.

The GO/PVA composites decompose in a two-stage process. The first step for significant mass loss, similarly to GO, starts at $\sim 150^{\circ} \mathrm{C}$, thus it can be assigned to the decomposition of $\mathrm{GO}$ alone. The addition of PVA can clearly improve the thermal stablity of GO. This is due to the extensive interfacial bonding developing between PVA and GO [26]. The second stage starting from $\sim 300{ }^{\circ} \mathrm{C}$ represents for the decomposition of PVA and exhibites as the sharp drop of mass loss, especially for the sample with higher PVA contents (3:3 and 3:5). Furthermore, all the GO/PVA composites exhibited better thermal stability than the PVA which can be also ascibed by the strong interfacial bondings. Similar observation was reported earlier for a $\mathrm{PVA} / \mathrm{SiO}_{2}$ nanocomposite [37].

\subsection{Phase structure}

Fig. 3a illustrates the XRD patterns of the GO, PVA and GO/PVA foams. The pure GO shows a broad peak at $10.69^{\circ}$, corresponding to a layer distance $0.826 \mathrm{~nm}$ between $\mathrm{GO}$ nanosheets. The PVA exhibits a wide peak at $\sim 19.63^{\circ}$, corresponding to its crystalline phase [18]. The broaden peak indicats its semi-crystalline structure.

For GO/PVA composites, the XRD patterns are different from both of pure GO and PVA. With the increase of PVA content, the GO peak in Zone I (Fig. 3a) shifted to the lower angle with reduced intensities, while the PVA peak in Zone II in Fig. 3a moved to the higher angle with enhanced intensities. When the $r_{\mathrm{GO} / \mathrm{PVA}}$ was $3: 1$ and $3: 3$, the peak of $\mathrm{GO}$ is 

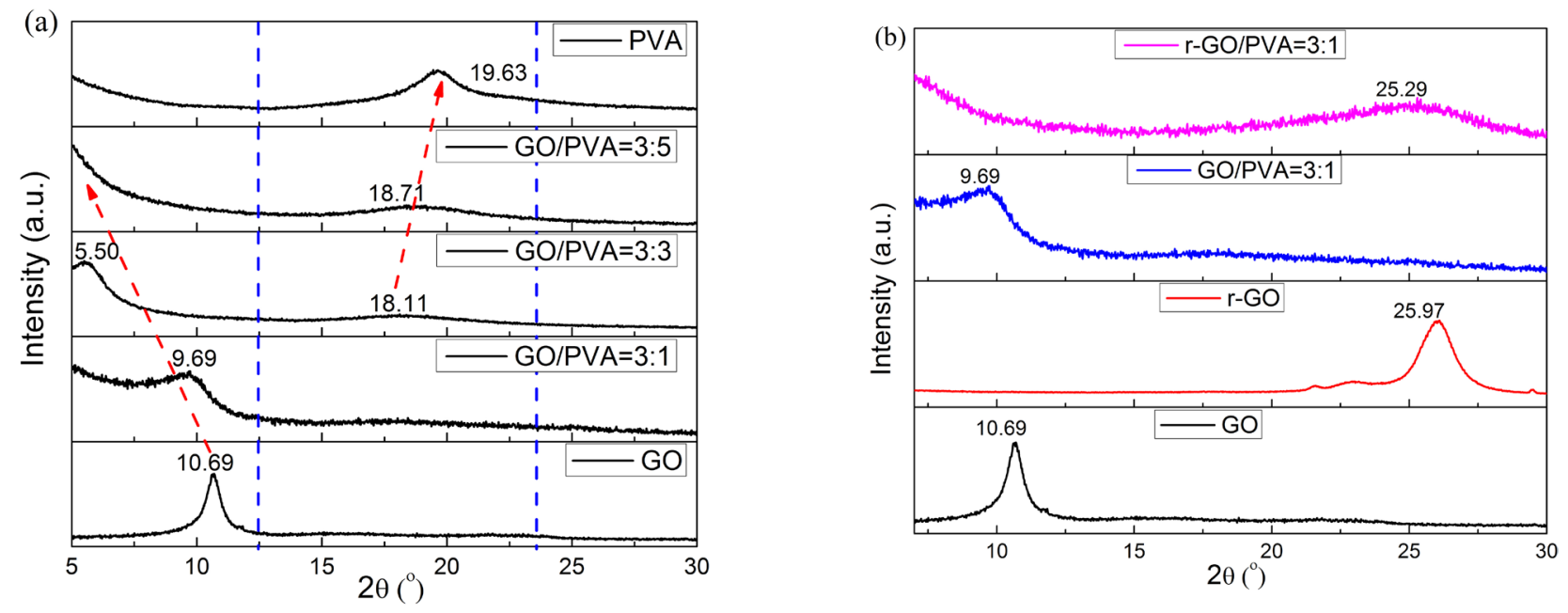

Fig. 3 XRD patterns of (a) pure GO, pure PVA and GO/PVA composites with $\mathrm{r}_{\mathrm{GO} / \mathrm{PVA}}$ of 3:1, 3:3 and 3:5 and (b) as-prepared and thermally reduced GO and GO/PVA foams with ratio $3: 1$.

$9.69^{\circ}$ and $5.50^{\circ}$, corresponding to the layer distance of 0.912 and $1.605 \mathrm{~nm}$, respectively. The increased width and the decreased intensity suggests the increased disorder of the GO layer structure. At $r_{\mathrm{GO} / \mathrm{PVA}}=3: 5$, this peak cannot be clearly detected. Meanwhile, the PVA peak in Zone II was barely seen at $\mathrm{r}_{\mathrm{GO} / \mathrm{PVA}}=3: 1$. With the increase of the PVA content, this peak moved to $18.11^{\circ}$ and $18.71^{\circ}$, at $\mathrm{r}_{\mathrm{GO} / \mathrm{PVA}}=3: 3$ and $3: 5$, respectively. These findings indicate that the added PVA molecules can intercalate GO nanosheets, leading in the increased spacing distances and the disorder of their structures. When the PVA content reaches over $50 \mathrm{wt} \%$, crystalline PVA appeares in the composites.

Fig. $3 \mathrm{~b}$ compares the effects of thermal reduction on the XRD patterns of GO and GO/PVA (3:1) foams. After the thermal treatment at $300{ }^{\circ} \mathrm{C}$ the GO peak was shifted to $\sim 25.97^{\circ}$ corresponding to graphite, similar to others' observation [29]. For r-GO/PVA, a much broader peak was observed at $25.29^{\circ}$. This suggests that not only graphene oxide was reduced, but also the PVA was subject to pyrolysis.

\subsection{Raman analysis}

Fig. 4 shows the typical Raman spectra of GO/PVA and r-GO/PVA foams. There are two strong bands at $\sim 1350$ and $1590 \mathrm{~cm}^{-1}$, corresponding to the D and G bands. These D and $\mathrm{G}$ bands are recognized as the presence of defects in the samples and the size of the in-plane sp2 domains, respectively. After thermal reduction, the $\mathrm{G}$ band shifted to $1580 \mathrm{~cm}^{-1}$ closing to the value of graphite, and the ratio between the intensities of the $\mathrm{D}$ and $\mathrm{G}$ bands $\left(\mathrm{I}_{\mathrm{D}} / \mathrm{I}_{\mathrm{G}}\right)$ increased slightly from 0.91 to 0.93 , indicating slightly more defects in the r-GO/PVA foam according to the Tuinstra relation, which proves that the $\mathrm{I}_{\mathrm{D}} /$ $I_{G}$ varies inversely with the size of the crystalline grains or inter-defect distance. [38]

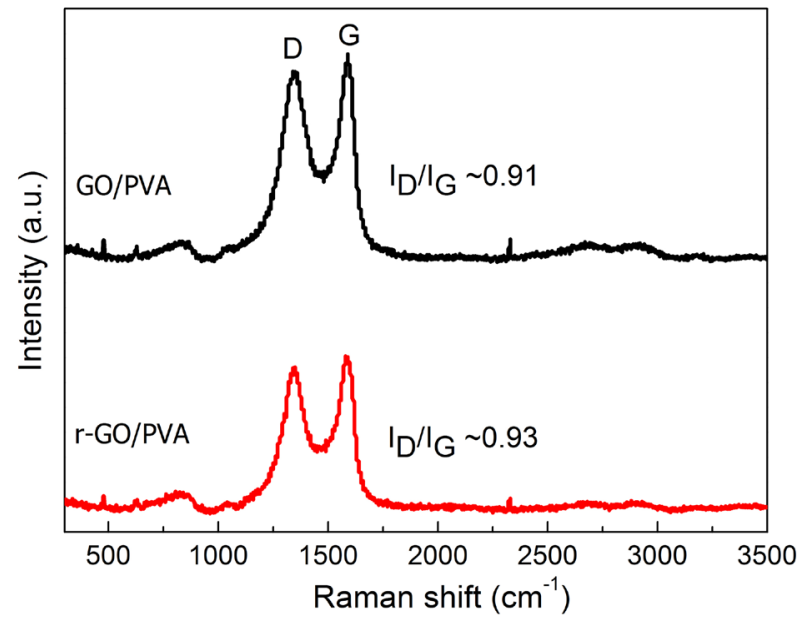

Fig. 4 Raman spectra of GO/PVA and r-GO/PVA composites. (GO: $P V A=3: 1)$.

\subsection{XPS analysis}

High resolution $\mathrm{C} 1 \mathrm{~s}$ and $\mathrm{O} 1 \mathrm{~s}$ spectra of $\mathrm{r}-\mathrm{GO} / \mathrm{PVA}$ foams were obtained by XPS. The overall surface composition (depicted in Fig. S1 Table S1, Supporting information) shows that almost similar amount of oxygen is removed by the heat treatment from both the GO and PVA samples. It is interesting to note that the extent of the reduction for the composite samples does not differ significantly from those of the constituents.

Fig. 5 shows the $\mathrm{O} 1 \mathrm{~s}$ and $\mathrm{C} 1 \mathrm{~s}$ spectra of the samples. It is clear that O1s of the $\mathrm{r}-\mathrm{GO}$ and the $\mathrm{r}-\mathrm{GO} / \mathrm{PVA}$ 3:1 consist of three major components and those of 3:3 and 3:5 samples consist of only two dominant components. It is not so obvious that O1s of the r-PVA is also composed of the two components but with different proportion. C1s spectra of the samples are much more complicated. While the sp2 component at 284.3 $\mathrm{eV}$ dominates the spectra of the r-GO and the r-GO/PVA 3:1, 

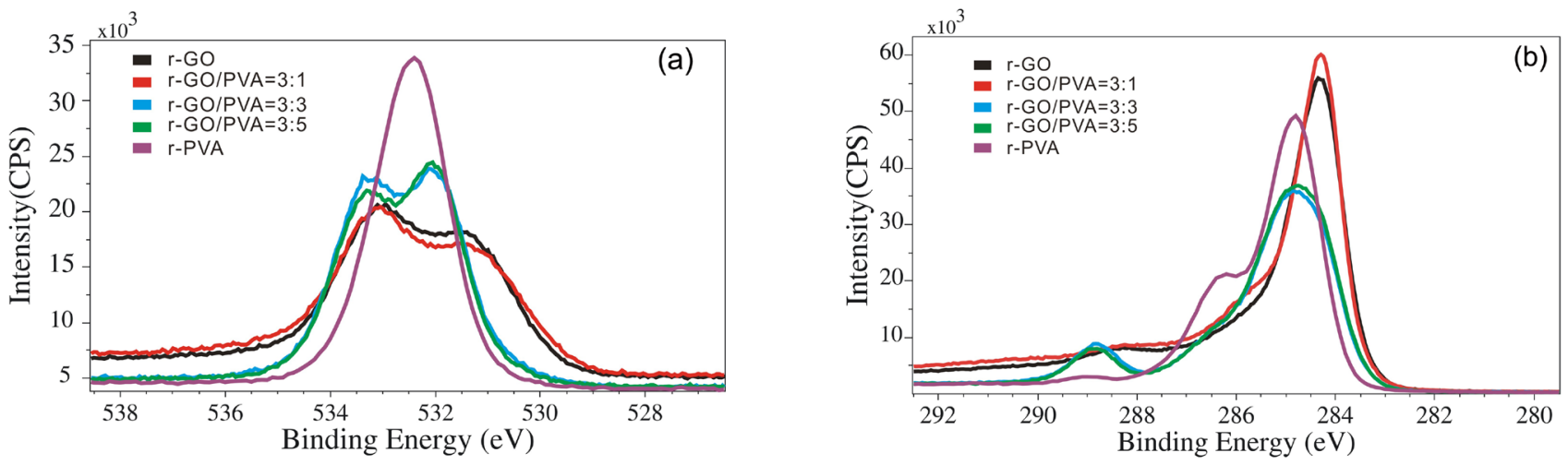

Fig. 5 Comparison of (a) O 1s and (b) C 1s spectra of thermally treated GO, PVA and GO/PVA composites with weight ratios 3:1, 3:3 and 3:5.

it is significantly reduced for the $3: 3$ and 3:5 composites and further reduced in the r-PVA. In the latter three samples the sp3 component at $284.9 \mathrm{eV}$ is dominant. Although it is not so obvious due to the shifted baseline, the component at 286.6 $\mathrm{eV}$ of these samples is also much more intense. It is important to note that the most shifted highest energy $\mathrm{C} 1 \mathrm{~s}$ component at about $288.8 \mathrm{eV}$ was developed only in the r-GO/PVA 3:3 and 3:5 samples. This suggested that at least one new reaction pathway was operative at the thermally activated interaction between the functional groups of the GO and of the PVA.

This qualitative information was supported in a quantitative manner by the accurate peak synthesis applying the minimum number of components of with similar energy position and of peak-widths of 1.2-1.4 eV and $1.1 \mathrm{eV}$ for the sp2 C1s (graphene) component. In fact, when the samples are built up of different nanoclusters with different functional groups, the chemical environment for the nearest bonded atoms may vary depending on the nature of the second neighbours. Thus the measurable energy shift of the specific peaks may vary significantly ( $0.3 \mathrm{eV}$ or even more) [24, 39-41]. An example of the peak synthesis of the $\mathrm{O} 1 \mathrm{~s}$ and $\mathrm{C} 1 \mathrm{~s}$ regions for the $\mathrm{rGO} / \mathrm{PVA}$ 3:3 sample is shown in Fig. S2 (Supporting information). As clearly seen, the summarised intensities of the peak components are accurately matching the recorded spectra.

In Table 1 the relative concentrations of the determined peaks are collected together with their $\mathrm{BE}(\mathrm{eV})$ and the proposed assignments of the bonding states. For the r-PVA sample it was found that the unreacted carbon ( $\mathrm{sp} 2$ and $\mathrm{sp} 3$ ) peaks were in the same energy positions, and the other $\mathrm{C} 1 \mathrm{~s}$ components were also only slightly different. The BE values of O1s components for this sample differ significantly: $\mathrm{O} 1$ is at $531.2 \mathrm{eV}$ and $\mathrm{O} 2$ is at $532.4 \mathrm{eV}$. The most intense components of the tabulated data are also shown in Fig. S3 (Supporting information).

The most obvious change is the inverse variation of the $\mathrm{sp} 2$ and sp3 carbon concentrations. It was found that $\mathrm{sp} 2$ for the r-PVA was diminishing. This cannot be attributed to the disappearance of the graphene environment, but the result of the screening effect of the PVA, decreasing the signal of the underlying GO. As the PVA molecular chains can evenly and completely surround the GO nanosheets, a core-shell structure can be formed and be preserved after heat treatment.

Analysing the other corresponding values of the $\mathrm{C} 1 \mathrm{~s}$ and O1s components a reasonable quantitative agreement was found. The importance of this is that it supports the validity of the suggested assignments of the peak components to specific chemical states.

The closest, almost exact correspondence was found between the $\mathrm{C} 5$ and $\mathrm{O} 2$ components both representing the $\mathrm{O}-\mathrm{C}=\mathrm{O}$ environment. The partner of $\mathrm{C} 3$, single bonded $\mathrm{C}-\mathrm{O}$, corresponded to the $\mathrm{O} 3$ component, in which part of this oxygen may be $\mathrm{C}-\mathrm{OH}$ and a smaller part is ether type $\mathrm{C}-\mathrm{O}-\mathrm{C}$. The

Table 1 The relative concentrations of the components by XPS analysis together with their BE (eV) and the proposed assignments of the bonding states for r-GO, r-PVA and r-GO/PVA composites with different weight ratios

\begin{tabular}{|c|c|c|c|c|c|c|c|c|c|}
\hline Peak (at.\%) & C 1 & $\mathrm{C} 2$ & C 3 & $\mathrm{C} 4$ & C 5 & O 1 & O 2 & O 3 & $\mathrm{O} 4$ \\
\hline B.E. $(\mathrm{eV})$ & $284.3 \pm 0.1$ & $284.9 \pm 0.1$ & $286.2 \pm 0.2$ & $287.3 \pm 0.3$ & $288.8 \pm 0.3$ & $530.6 \pm 0.1$ & $531.8 \pm 0.3$ & $533.3 \pm 0.3$ & $534.3 \pm 0.2$ \\
\hline Chemical state & sp2 C-C & sp3 C-C & $\mathrm{C}-\mathrm{O}$ & $\mathrm{C}=\mathrm{O}$ & $\mathrm{O}-\mathrm{C}=\mathrm{O}$ & $\mathrm{O}=\mathrm{Car}$ & $\mathrm{O}^{*}=\mathrm{C}-\mathrm{O}-\mathrm{C}$ & $\mathrm{C}-\mathrm{O} / \mathrm{C}-\mathrm{O}-\mathrm{C}$ & $\mathrm{O}=\mathrm{C}--\mathrm{O} * \mathrm{H}$ \\
\hline $\mathrm{r}-\mathrm{GO}$ & 52.3 & 15.5 & 9.5 & 2.9 & 5.1 & 2.4 & 4.7 & 7.0 & 0.6 \\
\hline r-GO/PVA 3:1 & 49.9 & 18.3 & 10.5 & 3.7 & 3.9 & 2.6 & 3.9 & 6.6 & 0.6 \\
\hline r-GO/PVA 3:5 & 27.6 & 34.6 & 11.1 & 3.2 & 6.8 & 0.9 & 7.7 & 7.5 & 0.5 \\
\hline r-PVA & 0.8 & 57.7 & 18.6 & 5.5 & 1.5 & $0.7^{*}$ & $12.4^{*}$ & 2.7 & 0.2 \\
\hline
\end{tabular}


right proportion of these two states could fill the difference between the $\mathrm{C} 3$ and $\mathrm{O} 3$ concentrations. The carbonyl type $\mathrm{C}=\mathrm{O}$ concentration is close to the oxygen connected to the aromatic carbon $\left(\mathrm{C}=\mathrm{O}_{\mathrm{ar}}\right)$ of the $\mathrm{GO}$. Accordingly this relation is only valid for the r-GO and r-GO/PVA 3:1 samples. The uncertainty of the position and concentration of smaller components does not allow to set up further relations among carbon and oxygen states. Development of other carboxylic or anhydride states is probable in these heat treated samples, what could be additionally connected with the small $\mathrm{C} 4$ and $\mathrm{O} 4$ peaks.

Formation of relatively large amount of $\mathrm{O}=\mathrm{C}-\mathrm{O}-\mathrm{C}$ bonds in the composite sample (3:3 and 3:5) suggests that in the presence of GO different reaction pathway opens at heat treatment, as compared to the PVA alone. The detected ether (C-O-C) and ester $(\mathrm{O}=\mathrm{C}-\mathrm{O}-\mathrm{C})$ type covalent bonds may be well formed between the GO and PVA clusters, in addition to the crosslinking among the long polymeric PVA chains. Development of these bonds would certainly contribute to the mechanical strengthening of the composites which will be discussed later.

\subsection{Microstructure}

Fig. 6 shows the typical microstructure of GO and r-GO foams prepared by the same method. The GO foam shows homogeneous pore structure with the size of $\sim 100 \mathrm{~mm}$. After being treated at $300^{\circ} \mathrm{C}$, the pore structure was inherited from the GO foam, however, the size of the pores was reduced down to $\sim 80 \mathrm{~mm}$ and cracks are clearly observed in Fig. $6 \mathrm{~b}$ due to the loss of strong bondings. [42]
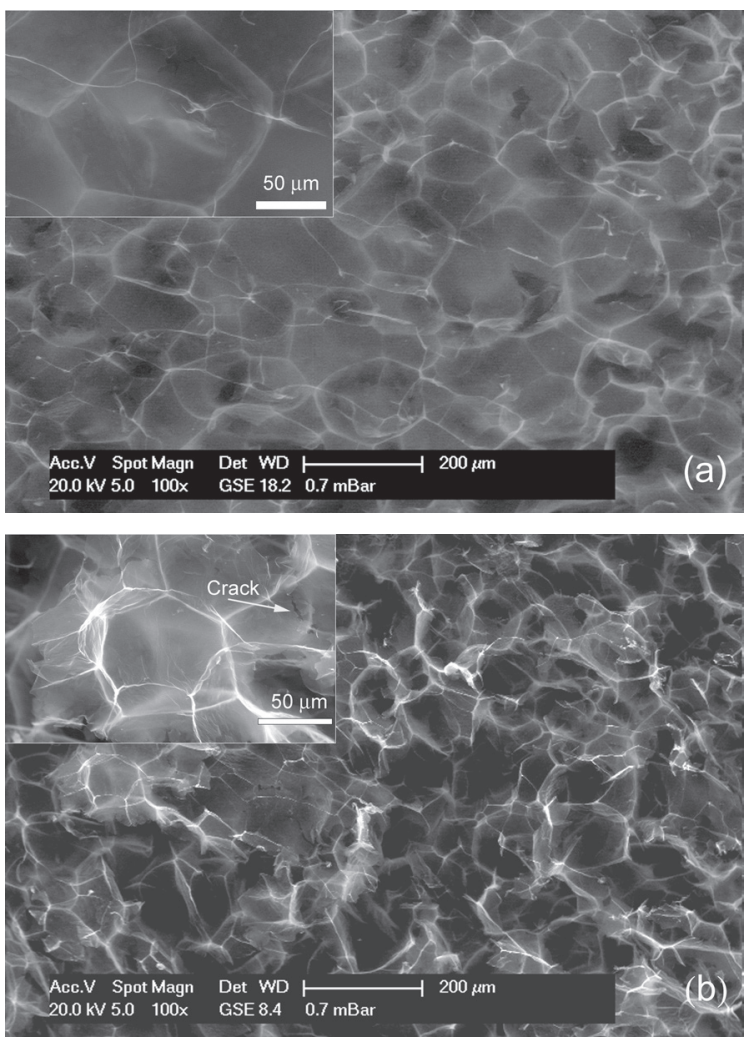

Fig. 6 SEM photos of (a) GO and (b) r-GO, which was reduced at $300^{\circ} \mathrm{C}$ in $\mathrm{Ar}$ atmosphere.
Fig. 7 compares the microstructure of r-GO/PVA foams with different PVA contents. It shows that the average size of pores is decreased with the increase of PVA content. As shown in Fig. 7a, the size of pores for the lowest PVA content $(\mathrm{rGO} /$ PVA=3:0.5) is $\sim 20 \mathrm{~mm}$, and decreases to $\sim 15 \mathrm{~mm}$ when the PVA content is increased to $25 \mathrm{wt} . \%\left(\mathrm{r}_{\mathrm{GO} / \mathrm{PVA}}=3: 1\right)$. Further increasing the PVA content, the average sizes of pores are decreased to $\sim 10$ $\mathrm{mm}$ and $\sim 8 \mathrm{~mm}$ for ratio $3: 3$ and 3:5, respectively. The convincing dependence of microstructure on the PVA content can be explained by the strong hydrogen bonding interaction between hydroxyl-rich PVA chains and oxygen-containing groups on GO sheets. Although GO nanosheets can contact with each other in their pure solution, the interaction force between them is weak. With the addition of the PVA component, the plenty of hydroxyl, epoxy and carboxyl groups on the surface of GO sheets can interact with the hydroxyl in PVA molecular chains by the formation of hydrogen bonding. [39, 43] In addition, one PVA chain can interact with two or more GO sheets, forming cross-linking sites. [28] The presence of PVA is thus critical for interconnecting the $\mathrm{GO}$ particles into stable 3D structures with reduced pore sizes. When the GO/PVA foams are thermally reduced, their spatial architecture can be inherited as demonstrated in Fig. 7, thus showing the decreasing pore size with the increase of PVA content.
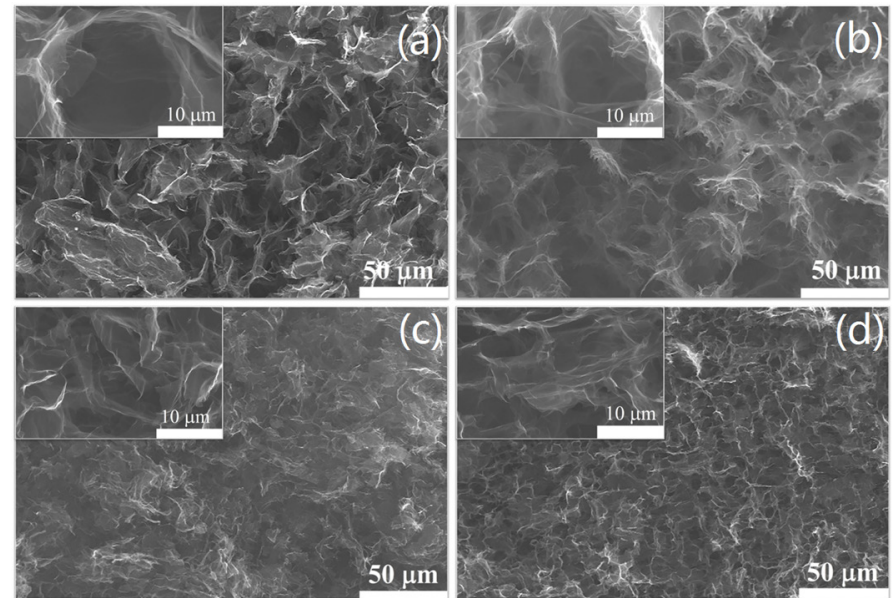

Fig. 7 SEM images of r-GO/PVA foams with different ratio (a) $3: 0.5$, (b) $3: 1$, (c) $3: 3$, (d) $3: 5$.

\subsection{Mechanical properties}

The typical compression stress-strain curves of $\mathrm{GO} /$ PVA and r-GO/PVA foams are shown in Fig. S4 (Supporting information). Both foams show the characteristics of porous materials including an initial linear region and a plateau with reduced slopes. The GO/PVA foam presented a $69 \%$ higher compression modulus $E_{\mathrm{c}}(0.49 \mathrm{MPa})$ than that of the $\mathrm{r}-\mathrm{GO} /$ PVA foam $(0.29 \mathrm{MPa})$ in the linear region. With the increase of the strain, different failure modes were observed. The GO/ PVA foam showed typical ductile failure as demonstrated in the inserts of Fig. S4a. With the strain up to $50 \%$, wrinkles of 
plastic deformation were clearly seen. For r-GO/PVA, macroscopic cracks were noticed when the strain reached $40 \%$. The foam was totally fractured at $50 \%$ strain. The above observations indicate that the thermal reduction changes the failure mechanism from the ductile plastic deformation to the brittle crack failure.

The influence of PVA contents on the compression stressstrain curves of the foams is shown in Fig. 8. For the pure GO foam, the $E_{\mathrm{c}}$ is $0.31 \mathrm{MPa}$ in Fig. 8c, slightly higher than the modulus $0.29 \mathrm{MPa}$ of the GO hydrogels prepared through hydrothermal and freeze casting by Xu et al. [6] For GO/PVA foams, the $E_{\mathrm{c}}$ increased with the increase of PVA content, and reached the highest value $1.53 \mathrm{MPa}$ for the r-GO/PVA 3:5 foam. This value is also higher than that of the pure PVA foam $(1.0 \mathrm{MPa})$ and the PVA nanocomposite with $0.8 \mathrm{wt} . \%$ GO (1.35 MPa) reported by Zhang et al. [24] The enhancement of mechanical properties with the rise of PVA content for the GO/PVA can be attributed to molecular-level dispersion and the strong hydrogen bonds between GO nanosheets and PVA chains, [41] which can efficiently transfer the external load. On the other hand, there were more bridges between the GO sheets due to the reduced pore sizes as shown in Fig. 7, which can support higher load.

After thermal reduction, compression modulus and strength were significantly decreased in Fig. $8 \mathrm{~b}$ and $8 \mathrm{~d}$, but still showing the increasing trend with the increase of PVA content. This is probably related to two effects. Firstly, the smaller pore size at higher PVA content (Fig. 7) could create more bridges between the r-GO sheets, thus exhibit better mechanical properties. Secondly, the PVA molecular chains have not been fully carburized at $\sim 300{ }^{\circ} \mathrm{C}$, thus the residual chain content can be higher when the PVA content is higher.
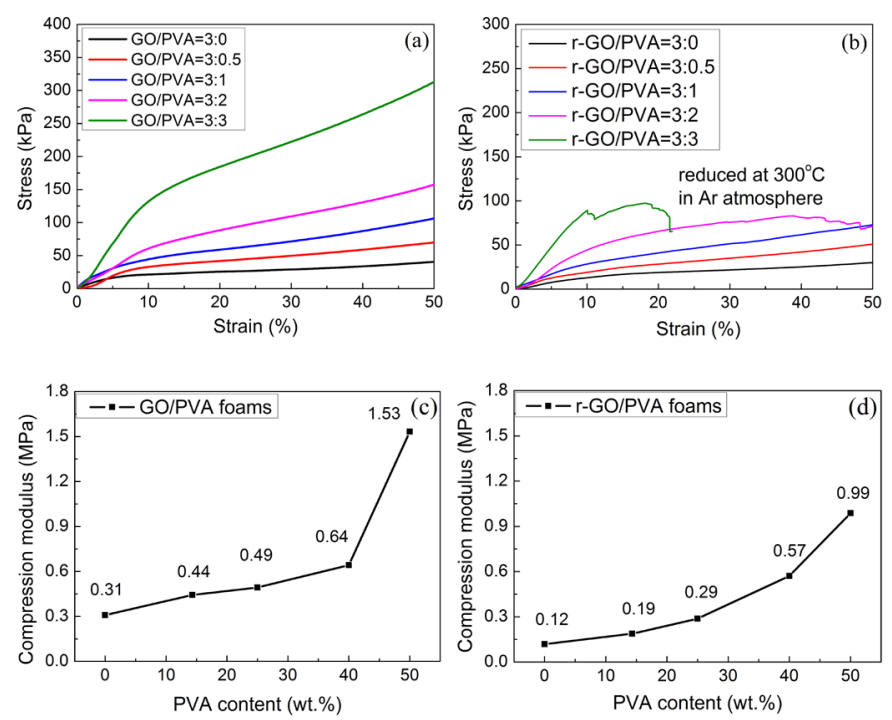

Fig. 8 Stress-strain curves of (a) GO/PVA and (b) r-GO/PVA foams with different PVA contents, compression modulus of (c) GO/PVA and (d) r-GO/PVA foams with different PVA contents.

\subsection{Electrical conductivity under compression strain}

Thermal reduction treatments can recover the electrical conductivity of non-conductive GO/PVA foams. The real-time electrical resistance under compression is shown in Fig. 9a. It can be seen that the resistance decreases rapidly when the strain is less than $6 \%$, which means the electrons can access to more channels when the foams were compressed. It can be ascribed that the (partly) carbonized pillars connecting the GO/graphene sheets are shrunk significantly at loading, resulting in higher cross-section area for current flow. Additionally, direct electrical contacts may be formed among the graphene sheets, or at least, very close connection allowing tunnelling as presented in Fig. 9b.

The stable resistance at $20 \%$ strain was increased from 4 to $60 \Omega$ with the increase of the original PVA content. This indicated that while the conductivity of PVA can be increased by pyrolysis, it is less than that by the reduction of GO nanosheets. Recalling the XPS results, the number of the sp3 C-C bonds was increased with the PVA content which can decrease the mobility of the electrons among the graphene planes.

Cyclic compression tests were also carried out to investigate the stability of electrical properties for the r-GO/PVA 3:5 foam. As shown in Fig. S5(Supporting information), when the maximum strain is $\sim 15 \%$ the stress-strain curves almost overlap by each other after the third time compression and remained almost invariable for 50 cycles. Meanwhile, the peak electrical current during each cycle was slightly increased and became stable after 35 cycles. These results suggested the good rebound resilience of the foams.
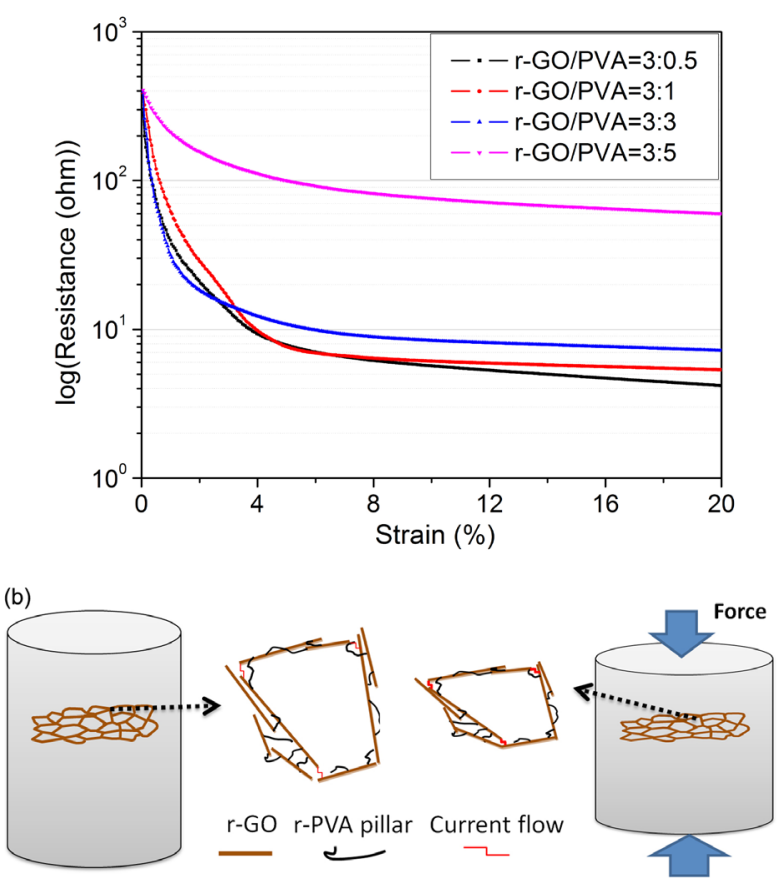

Fig. 9 (a) The real-time electrical resistance vs. strain under compression for r-GO/PVA foams with different proportions, (b) schematic diagram for the structure change showing enhanced conductivity 


\subsection{Electrochemical behaviour}

The electrochemical performance of r-GO/PVA (3:1, $300^{\circ} \mathrm{C}$ ) foams was initially investigated by cyclic voltammetry $(\mathrm{CV})$ at a scan rate of $0.5 \mathrm{mV} \mathrm{s}^{-1}$ in the potential range of $0 \sim 3 \mathrm{~V}$ in Fig. 10a. In the first cycle, an obvious cathodic peak at about $0.01 \mathrm{~V}$ can be attributed to the insertion of lithium ion in graphene and the formation of irreversible solid electrolyte interface (SEI) film. A broad anodic peak is observed around $0.01 \sim 1.0 \mathrm{~V}$, corresponding to lithium extraction from graphene. In the subsequent cycles, it is important to note that the peak potentials remained similar, and the peak intensity decreased very slightly, which indicated significant reversibility and reproducibility of the electrode.
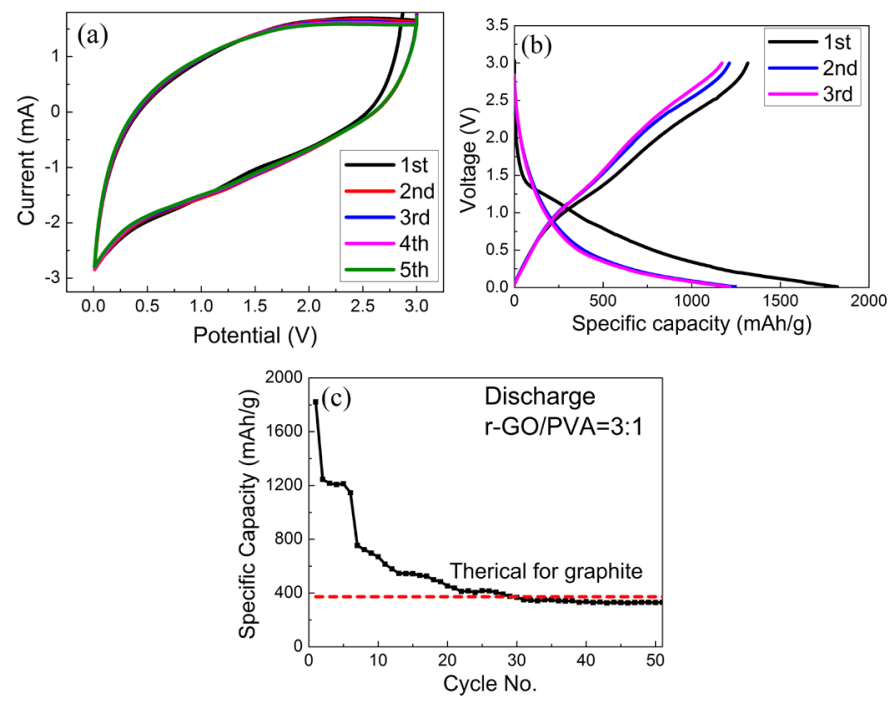

Fig. 10 Electrochemical properties of the r-GO/PVA (3:1) foams which was reduced at $300{ }^{\circ} \mathrm{C}$ in Ar atmosphere: (a) CV curves, (b) discharge/charge curves for the initial three cycles and (c) cycling performance at a current density of $50 \mathrm{~mA} \mathrm{~g}^{-1}$.

To demonstrate the potential application of the $\mathrm{r}-\mathrm{GO} / \mathrm{PVA}$ $\left(3: 1,300^{\circ} \mathrm{C}\right)$ foams as a LIBs anode, the galvanostatic measurements were operated in the voltage range of 0 to $3.0 \mathrm{~V}$ (vs. $\mathrm{Li} / \mathrm{Li}^{+}$) at a current density of $50 \mathrm{~mA} \mathrm{~g}^{-1}$. Fig. 10b shows the discharge/charge curves in the initial three cycles. In the first discharge process, an extended voltage plateau can be observed at 1.3-0.01 V, which is caused by the lithium insertion in graphene and the formation of SEI film. In the charge process, the sloped region can be attributed to the reverse reaction for lithium extraction from graphene, which is in good agreement with the $\mathrm{CV}$ analysis.

The initial discharge and charge capacities of $\mathrm{r}-\mathrm{GO} / \mathrm{PVA}$ $\left(3: 1,300^{\circ} \mathrm{C}\right)$ electrode are 1822 and $1316 \mathrm{~mA} \mathrm{~h} \mathrm{~g}^{-1}$, the initial Columbic efficiency is $72 \%$ and the initial large capacity loss may result from the formation of an SEI film and the reaction of lithium ion with residual oxygen-containing functional groups. [42, 43] However, the 3:1 r-GO/PVA electrode retained a high reversible capacity of $1216 \mathrm{~mA} \mathrm{~h} \mathrm{~g}^{-1}$ after 3 cycles. The high capacity can be attributed to the porous structure which provided more lithium insertion active sites than commercial graphite. Besides, the SEI film is the main reason for the initial low Columbic efficiency and large capacity loss during the initial cycle. However, the Columbic efficiency of r-GO/PVA (3:1) soared from $72 \%$ in the first cycle to $97 \%$ in the second cycle and then remained above $96 \%$ in the subsequent cycles. These results indicate that the 3D construction is helpful in improving the electronic conductivity along with the Li diffusion kinetics during the electrochemical reaction.

Another advantage of the r-GO/PVA electrode is its improved cycling performance, which is illustrated in Fig. 10c. The r-GO/PVA foam presents good cycling performance. After 50 discharge/charge cycles, the reversible capacity still maintains more than $330 \mathrm{~mA} \mathrm{~h} \mathrm{~g}^{-1}$, which is comparable to the theoretical value of graphite $\left(372 \mathrm{~mA} \mathrm{~h} \mathrm{~g}^{-1}\right)$. The good electrochemical performance of the r-GO/PVA can be summarized as follows: (i) the graphene foams have an excellent electrical conductivity and act as the conductive bridges, which can reduce the inner resistance of the batteries. (ii) The 3D cross-linking hierarchical structure of the composites not only serves as an elastic buffer space to alleviate the volume change resulting from $\mathrm{Li}$ insertion/desertion during the charge/discharge process, but also efficiently prevent the agglomeration of graphene sheets. (iii) The large surface area of 3D construction are beneficial to enlarging the electrode/electrolyte contact area, shortening the path length for lithium transport.

According to the above discussions, we are convinced that the $3 \mathrm{D}$ porous structure with superior mechanical properties is responsible for enhancing the electrochemical performance of r-GO/PVA based composites. More generally, the present studies provide a promising strategy combining $\mathrm{r}-\mathrm{GO}$ foams with other electrode materials for the application in high performance lithium-ion batteries. We have a great expectation that the $\mathrm{r}-\mathrm{GO} / \mathrm{PVA}$ foams with stable mechanical performance can be composited with other nanoparticles to further improve its application in LIBs.

\section{Conclusions}

In this study, GO/PVA foams synthesized by solution mixture and freeze-drying methods were successfully made. The added PVA molecules can intercalate GO nanosheets, leading in the increased spacing distances and the disorder of their structures. Moreover, the resulted microstructures of the $\mathrm{GO} /$ PVA foams were influenced by the addition of PVA, as showing the reduced pores sizes with the increase of PVA content due to the strong hydrogen bonding interaction between hydroxyl-rich PVA chains and oxygen-containing groups on GO sheets. The mechanical properties of GO/PVA are thus increased.

With the thermal reduction at $300^{\circ} \mathrm{C}$, the PVA molecules were partially subjected to pyrolysis and the reduced GO/PVA foams showed similar 3D architecture. XPS analysis showed the inverse variation of the $\mathrm{sp} 2$ and $\mathrm{sp} 3$ carbon concentration in 
terms of the PVA content. Their mechanical properties were also increased with the original PVA content. Although the properties were decreased after reduction, good structure cyclic stability up to $18 \%$ compression strain was found for the r-GO/PVA 3:5.

The r-GO/PVA foams showed excellent electrical conductivity. As the anode of the lithium ion battery, the initial discharge capacity for $\mathrm{r}-\mathrm{GO} / \mathrm{PVA}$ (3:1) foams is $1822 \mathrm{~mA} \mathrm{~h} \mathrm{~g}^{-1}$ and remains more than $330 \mathrm{~mA} \mathrm{~h} \mathrm{~g}^{-1}$ after 50 cycles.

\section{Acknowledgements}

The authors would like to thank the financial supports by National Natural Science Foundation of China (\#11472080 and \#11204031), the Natural Science Foundation of Jiangsu Province of China (\#BK20141336), the Hungarian National Scientific Research Fund (OTKA) (\#K-109558) and Jiangsu Key Laboratory for Advanced Metallic Materials (\#BM2007204).

\section{References}

[1] Novoselov, K. S., Geim, A. K., Morozov, S. V., Jiang, D., Zhang, Y., Dubonos, S. V., Grigorieva, I. V., Firsov, A. A. "Electric field effect in atomically thin carbon films." Science. 306(5696), pp. 666-669. 2004. https://doi.org/10.1126/science.1102896

[2] Geim, A. K. "Graphene: Status and Prospects." Science. 324(5934), pp. 1530-1534. 2009. https://doi.org/10.1126/science.1158877

[3] Zhu, Z. P., Su, D. S., Weinberg, G., Schlogl, R. "Supermolecular self-assembly of graphene sheets: Formation of tube-in-tube nanostructures." Nano Letters. 4(11), pp. 2255-2259. 2004 https://doi.org/10.1021/n1048794t

[4] Wang, H., Wang, X., Li, X., Dai, H. "Chemical Self-Assembly of Graphene Sheets." Nano Research. 2(4), pp. 336-342. 2009. https://doi.org/10.1007/s12274-009-9031-x

[5] Li, B., Cao, X., Ong, H. G., Cheah, J. W., Zhou, X., Yin, Z., Li, H., Wang, J., Boey, F., Huang, W., Zhang, H. "All-Carbon Electronic Devices Fabricated by Directly Grown Single-Walled Carbon Nanotubes on Reduced Graphene Oxide Electrodes." Advanced Materials. 22(28), pp. 3058-3061. 2010.

https://doi.org/10.1002/adma.201000736

[6] Xu, Y., Sheng, K., Li, C., Shi, G. "Self-Assembled Graphene Hydrogel via a One-Step Hydrothermal Process." ACS Nano. 4(7), pp. 43244330. 2010

https://doi.org/10.1021/nn101187z

[7] Chen, Z., Ren, W., Gao, L., Liu, B., Pei, S., Cheng, H. "Threedimensional flexible and conductive interconnected graphene networks grown by chemical vapour deposition." Nature Materials. 10(6), pp. 424-428. 2011.

https://doi.org/10.1038/NMAT3001

[8] Schedin, F., Geim, A. K., Morozov, S. V., Hill, E. W., Blake, P., Katsnelson, M. I., Novoselov, K. S. "Detection of individual gas molecules adsorbed on graphene." Nature Materials. 6(9), pp. 652-655. 2007.

https://doi.org/10.1038/nmat1967

[9] Yuan, J., Liu, X., Akbulut, O., Hu, J., Suib, S. L., Kong, J., Stellacci, F. "Superwetting nanowire membranes for selective absorption." Nature Nanotechnology. 3(6), pp. 332-336. 2008. https://doi.org/10.1038/nnano.2008.136
[10] Rogers, J. A., Someya, T., Huang, Y. "Materials and Mechanics for Stretchable Electronics." Science. 327(5973), pp. 1603-1607. 2010. https://doi.org/10.1126/science.1182383

[11] Kim, H. Y., Jeong, S., Jeong, S. Y., Baeg, K., Han, J. T., Jeong, M. S., Lee, G., Jeong, H. J. "Chemically doped three-dimensional porous graphene monoliths for high-performance flexible field emitters." Nanoscale. 7(12), pp. 5495-5502. 2015.

https://doi.org/10.1039/c4nr07189a

[12] Zhao, X., Zhang, Q., Chen, D., Lu, P. "Enhanced Mechanical Properties of Graphene-Based Poly(vinyl alcohol) Composites." Macromolecules. 43(5), pp. 2357-2363. 2010 https://doi.org/10.1021/ma902862u

[13] Zhang, H., Yan, Q., Zheng, W., He, Z., Yu, Z. "Tough Graphene-Polymer Microcellular Foams for Electromagnetic Interference Shielding." ACS Applied Materials \& Interfaces. 3(3), pp. 918-924. 2011. https://doi.org/10.1021/am200021v

[14] Dong, X., Xu, H., Wang, X., Huang, Y., Chan-Park, M. B., Zhang, H., Wang, L., Huang, W., Chen, P. "3D Graphene-Cobalt Oxide Electrode for High-Performance Supercapacitor and Enzymeless Glucose Detection." ACS Nano. 6(4), pp. 3206-3213. 2012.

https://doi.org/10.1021/nn300097q

[15] Huang, X., Qian, K., Yang, J., Zhang, J., Li, L., Yu, C., Zhao, D. "Functional Nanoporous Graphene Foams with Controlled Pore Sizes." Advanced Materials. 24(32), pp. 4419-4423. 2012. https://doi.org/10.1002/adma.201201680

[16] Liu, K., Chen, Y., Policastro, G. M., Becker, M. L., Zhu, Y. "ThreeDimensional Bicontinuous Graphene Monolith from Polymer Templates." ACS Nano. 9(6), pp. 6041-6049. 2015. https://doi.org/10.1021/acsnano.5b01006

[17] Murray, E., Sayyar, S., Thompson, B. C., Gorkin, R. I., Officer, D. L., Wallace, G. G. "A bio-friendly, green route to processable, biocompatible graphene/polymer composites." RSC Advances. 5(56), pp. 4528445290. 2015

https://doi.org/10.1039/c5ra07210g

[18] Chen, X., Wei, W., Lv, W., Su, F., He, Y., Li, B., Kang, F., Yang, Q. "A graphene-based nanostructure with expanded ion transport channels for high rate Li-ion batteries." Chemical Communications. 48(47), pp. 5904-5906. 2012.

https://doi.org/10.1039/c2cc32276e.

[19] Chen, W., Yan, L. "In situ self-assembly of mild chemical reduction graphene for three-dimensional architectures". Nanoscale. 3(8), pp. 3132-3137. 2011. https://doi.org/10.1039/c1nr10355e

[20] Sun, H., Xu, Z., Gao, C. "Multifunctional, Ultra-Flyweight, Synergistically Assembled Carbon Aerogels." Advanced Materials. 25(18), pp. 2554-2560. 2013. https://doi.org/10.1002/adma.201204576

[21] Vickery, J. L., Patil, A. J., Mann, S. "Fabrication of GraphenePolymer Nanocomposites With Higher-Order Three-Dimensional Architectures." Advanced Materials. 21(21), pp. 2180. 2009. https://doi.org/10.1002/adma.200803606

[22] Yang, L., Wang, Z., Ji, Y., Wang, J., Xue, G. "Highly Ordered 3D Graphene-Based Polymer Composite Materials Fabricated by "Particle-Constructing" Method and Their Outstanding Conductivity." Macromolecules. 47(5), pp. 1749-1756. 2014. https://doi.org/10.1021/ma402364r

[23] Yang, X., Li, L., Shang, S., Tao, X. "Synthesis and characterization of layer-aligned poly(vinyl alcohol)/graphene nanocomposites." Polymer. 51(15), pp. 3431-3435. 2010. https://doi.org/10.1016/j.polymer.2010.05.034 
[24] Zhang, L., Wang, Z., Xu, C., Li, Y., Gao, J., Wang, W., Liu, Y. "High strength graphene oxide/polyvinyl alcohol composite hydrogels." Journal of Materials Chemistry. 21(28), pp. 10399. 2011. https://doi.org/10.1039/c0jm04043f

[25] Ye, S., Feng, J., Wu, P. "Highly elastic graphene oxide-epoxy composite aerogels via simple freeze-drying and subsequent routine curing." Journal of Materials Chemistry A. 1(10), pp. 3495-3502. 2013. https://doi.org/10.1039/c2ta01142e

[26] Chen, J., Gao, Y., Liu, W., Shi, X., Li, L., Wang, Z., Zhang, Y., Guo, X., Liu, G., Li, W., Beake, B. D. "The influence of dehydration on the interfacial bonding, microstructure and mechanical properties of poly(vinyl alcohol)/graphene oxide nanocomposites." Carbon. 94, pp. 845-855. 2015.

https://doi.org/10.1016/j.carbon.2015.07.068

[27] Liang, J., Huang, Y., Zhang, L., Wang, Y., Ma, Y., Guo, T., Chen, Y. "Molecular-level dispersion of graphene into poly (vinyl alcohol) and effective reinforcement of their nanocomposites." Advanced Functional Materials. 19(14), pp. 2297-2302. 2009.

[28] Bai, H., Li, C., Wang, X., Shi, G. "A pH-sensitive graphene oxide composite hydrogel." Chemical Communications. 46(14), pp. 2376-2378. 2010. https://doi.org/10.1039/c000051e

[29] Kim, J. E., Lee, H. S. "Oscillatory shear induced gelation of graphene-poly(vinyl alcohol) composite hydrogels and rheological premonitor of ultra-light aerogels." Polymer. 55(1SI), pp. 287-294. 2014. https://doi.org/10.1016/j.polymer.2013.11.011

[30] Cao, X., Shi, Y., Shi, W., Lu, G., Huang, X., Yan, Q., Zhang, Q., Zhang, H. "Preparation of Novel 3D Graphene Networks for Supercapacitor Applications." Small. 7(22), pp. 3163-3168. 2011. https://doi.org/10.1002/sml1.201100990

[31] Li, N., Chen, Z., Ren, W., Li, F., Cheng, H. "Flexible graphene-based lithium ion batteries with ultrafast charge and discharge rates." Proceedings of the National Academy of Sciences of the United States of America. 109(43), pp. 17360-17365. 2012. https://doi.org/10.1073/pnas.1210072109

[32] Chen, W., Li, S., Chen, C., Yan, L. "Self-Assembly and Embedding of Nanoparticles by In Situ Reduced Graphene for Preparation of a 3D Graphene/Nanoparticle Aerogel." Advanced Materials. 23(47), pp. 5679. 2011. https://doi.org/10.1002/adma.201102838

[33] Marcano, D. C., Kosynkin, D. V., Berlin, J. M., Sinitskii, A., Sun, Z., Slesarev, A., Alemany, L. B., Lu, W., Tour, J. M. "Improved Synthesis of Graphene Oxide." ACS Nano. 4(8), pp. 4806-4814. 2010. https://doi.org/10.1021/nn1006368
[34] Mohai, M. "XPS MultiQuant: multimodel XPS quantification software." Surface and Interface Analysis. 36(8), pp. 828-832. 2004. https://doi.org/10.1002/sia.1775

[35] Verdejo, R., Lamoriniere, S., Cottam, B., Bismarck, A., Shaffer, M. "Removal of oxidation debris from multi-walled carbon nanotubes." Chemical Communications. 5, pp. 513-515. 2007. https://doi.org/10.1039/b611930a

[36] Lee, J., Ahn, H., Yoon, J., Jang, J. "Three-dimensional nano-foam of few-layer graphene grown by CVD for DSSC." Physical Chemistry Chemical Physics. 14(22), pp. 7938-7943. 2012. https://doi.org/10.1039/c2cp40810d.

[37] Peng, Z., Kong, L. X. "A thermal degradation mechanism of polyvinyl alcohol/silica nanocomposites." Polymer Degradation and Stability. 92(6), pp. 1061-1071. 2007. https://doi.org/10.1016/j.polymdegradstab.2007.02.012

[38] Paredes, J. I., Villar-Rodil, S., Solis-Fernandez, P., MartinezAlonso, A., Tascon, J. M. D. "Atomic Force and Scanning Tunneling Microscopy Imaging of Graphene Nanosheets Derived from Graphite Oxide." Langmuir. 25(10), pp. 5957-5968. 2009. https://doi.org/10.1021/la804216z.

[39] Pei, S., Cheng, H. "The reduction of graphene oxide." Carbon. 50(9), pp. 3210-3228. 2012. https://doi.org/10.1016/j.carbon.2011.11.010

[40] Zhang, L., Zhang, F., Yang, X., Long, G., Wu, Y., Zhang, T., Leng, K., Huang, Y., Ma, Y., Yu, A., Chen, Y. "Porous 3D graphene-based bulk materials with exceptional high surface area and excellent conductivity for supercapacitors." Scientific Reports. 3(1408). 2013. https://doi.org/10.1038/srep01408

[41] Du, J., Cheng, H. "The Fabrication, Properties, and Uses of Graphene/ Polymer Composites." Macromolecular Chemistry and Physics. 213(10-11SI), pp. 1060-1077. 2012. https://oi.org/10.1002/macp.201200029

[42] Aurbach, D. "Review of selected electrode-solution interactions which determine the performance of $\mathrm{Li}$ and $\mathrm{Li}$ ion batteries." Journal of Power Sources. 89(2), pp. 206-218. 2000. https://doi.org/10.1016/S0378-7753(00)00431-6

[43] Zhou, H. S., Zhu, S. M., Hibino, M., Honma, I., Ichihara, M. "Lithium storage in ordered mesoporous carbon (CMK-3) with high reversible specific energy capacity and good cycling performance." Advanced Materials. 15(24), pp. 2107-2111. 2003. https://doi.org/10.1002/adma.200306125 


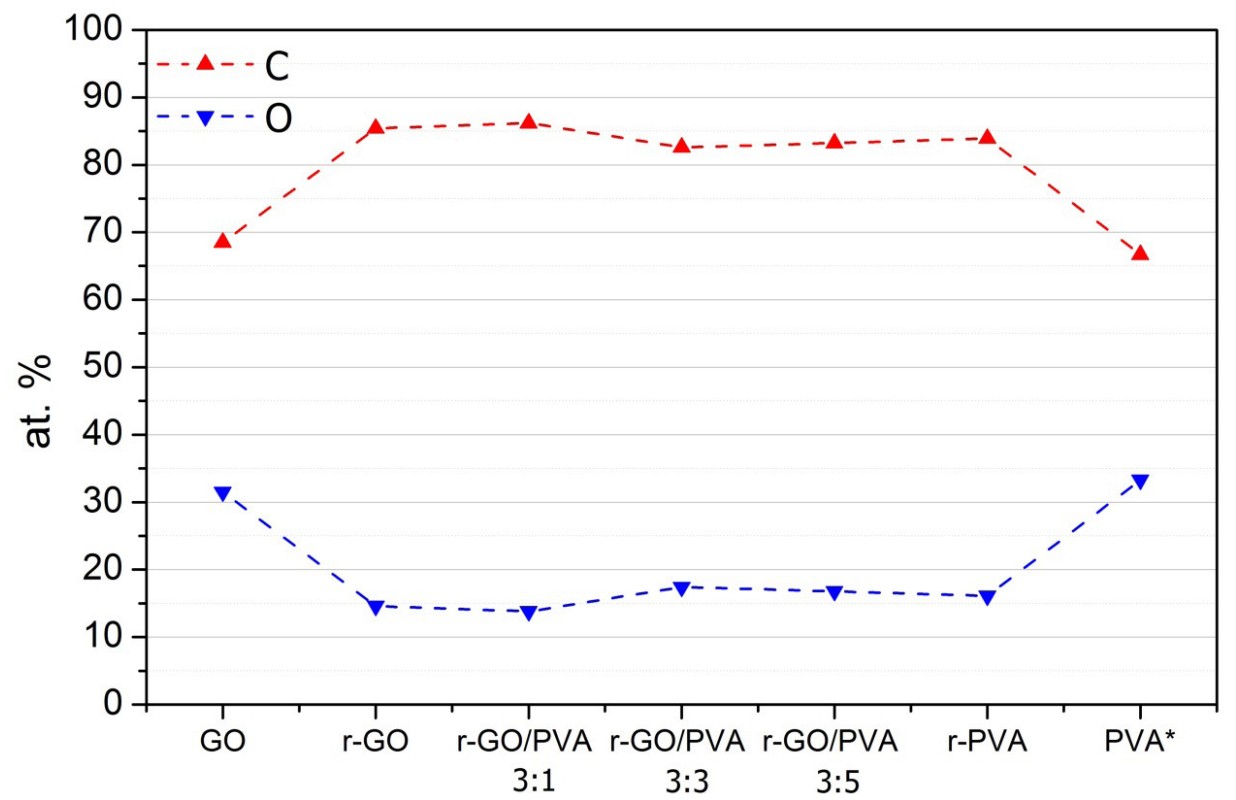

Fig. S1 Chemical compositions for the GO, r-GO and r-GO/PVA composites analyzed by XPS with the nominal composition of untreated PVA
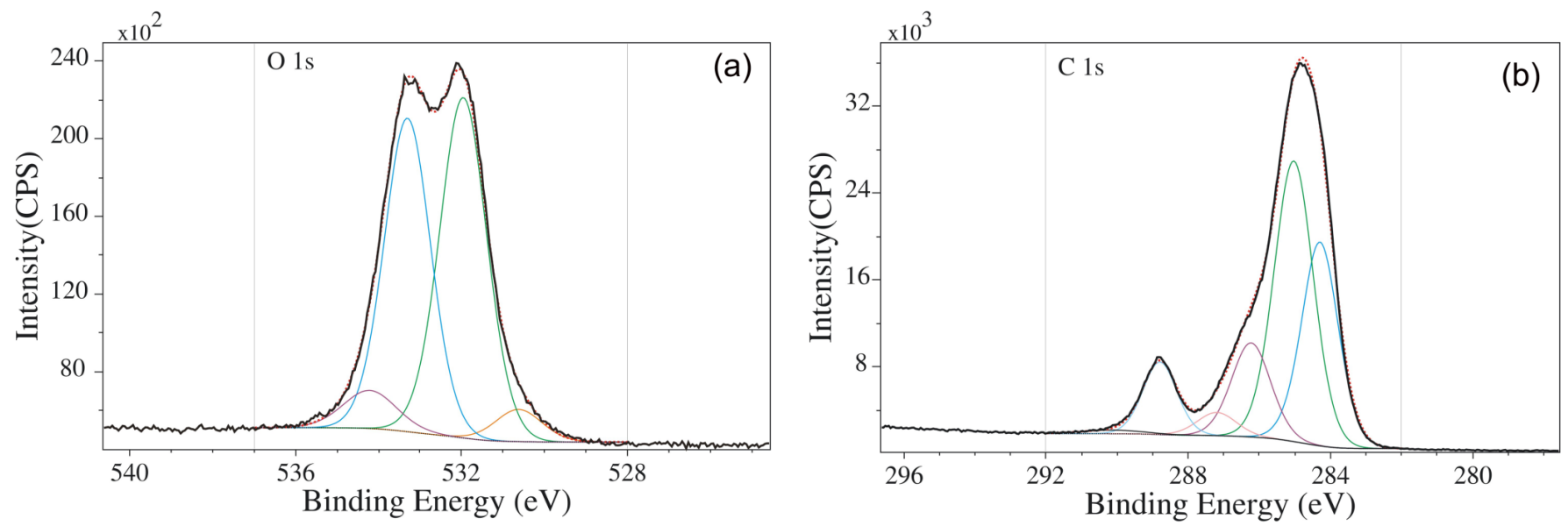

Fig. S2 Typical perk synthesis of (a) O 1sand (b) C 1s regions for the r-GO/PVA 3:3, showing complete coincidence of the sum of the component peaks with the experimental data. 


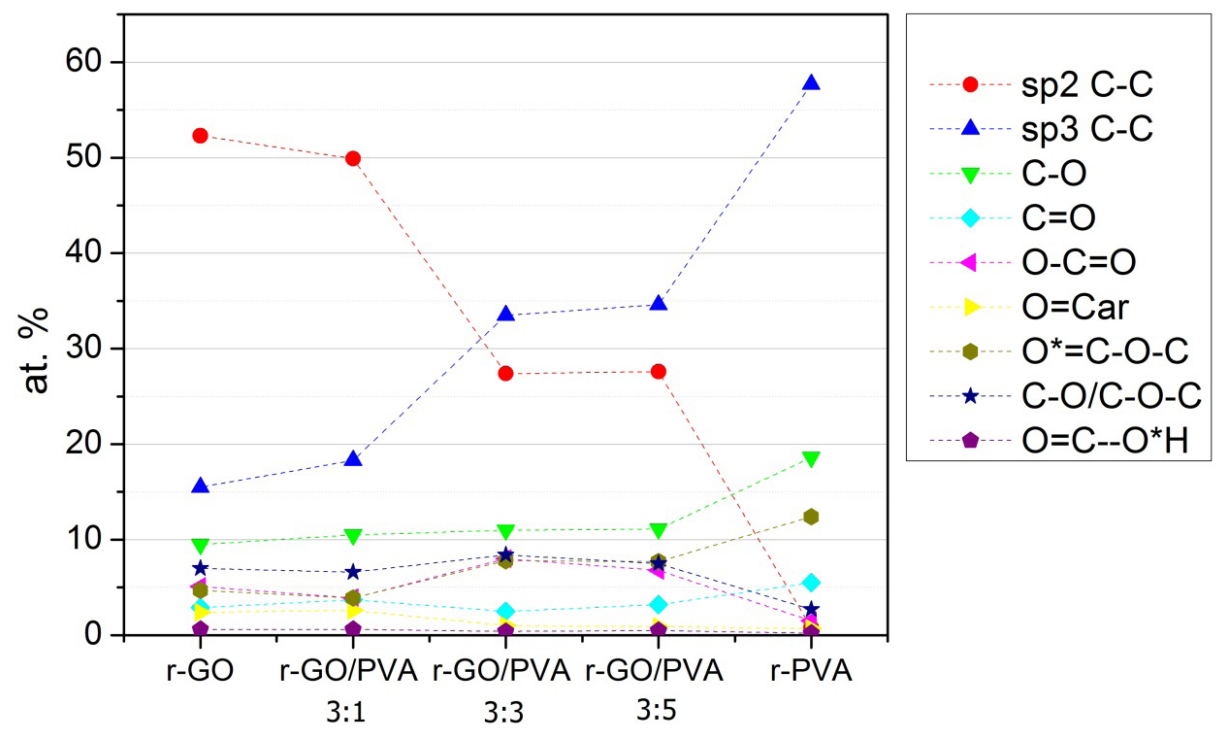

Fig. S3 Graphical representation of the change of the concentration of individual peaks showing the gradual changes by the increasing PVA content in the composites.
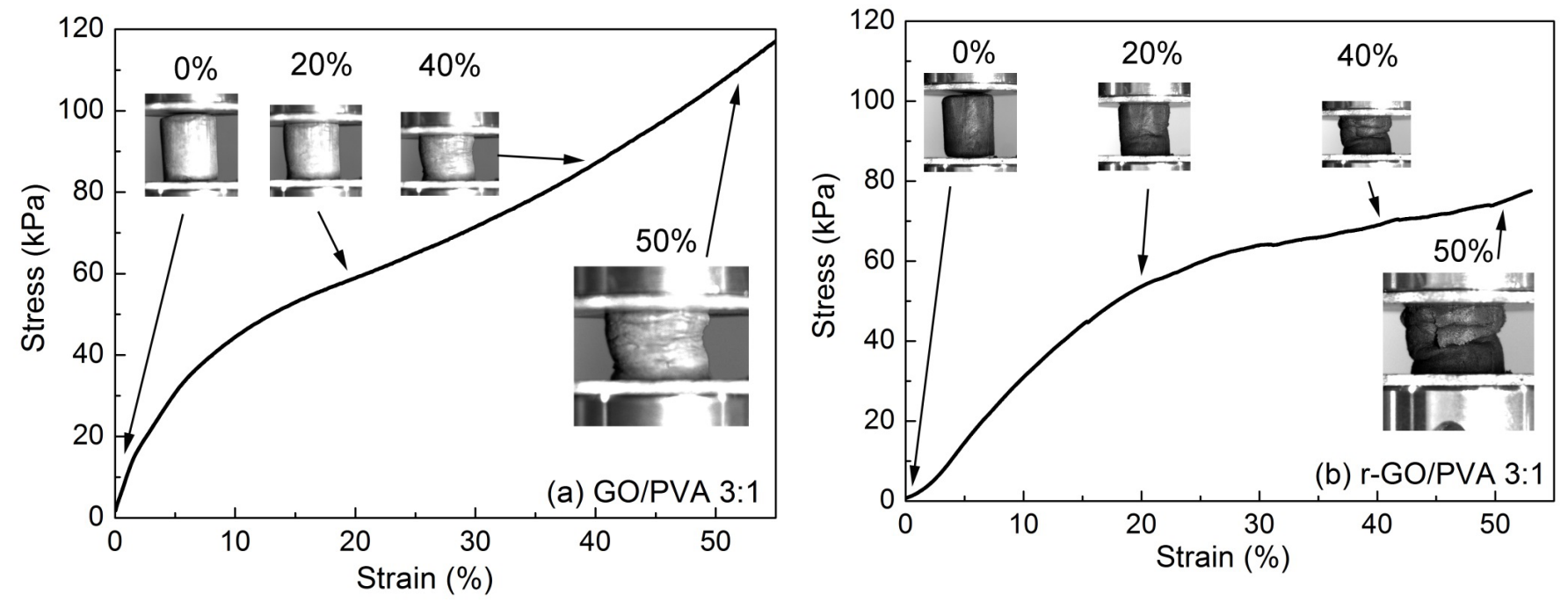

Fig. S4 Typical stress-strain curve of 3:1 proportion of (a) GO/PVA and (b) r-GO/PVA composites
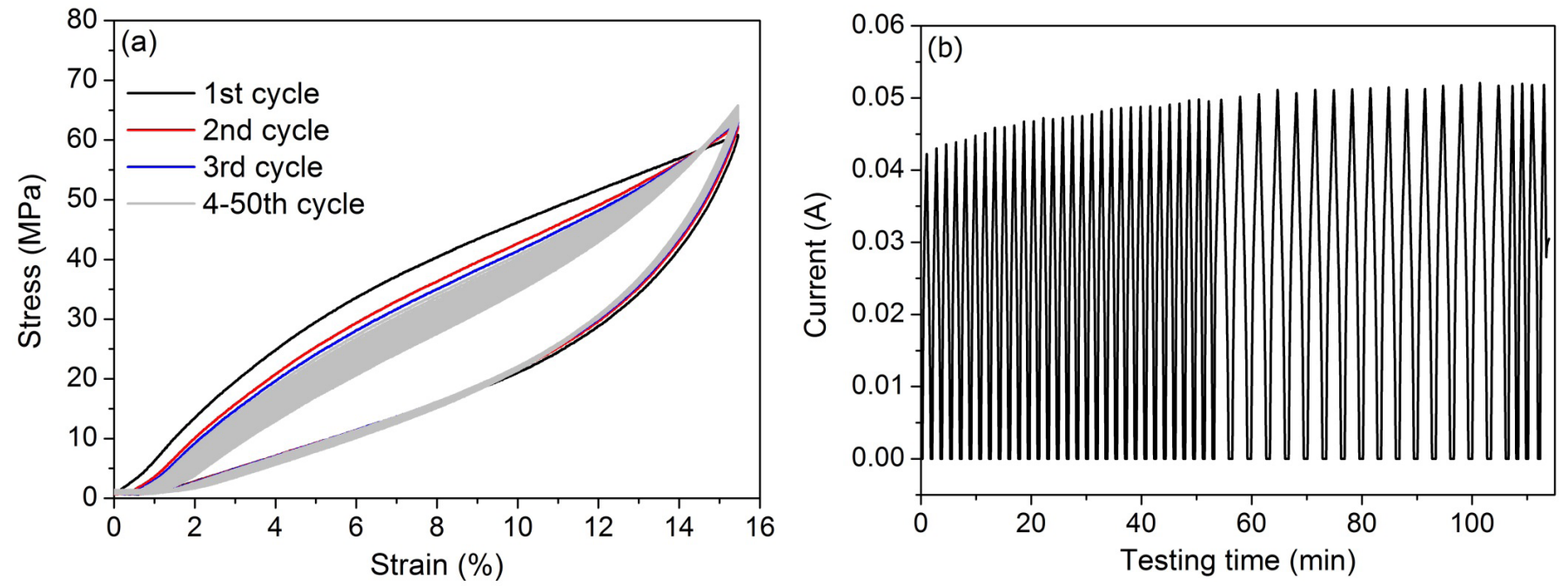

Fig. S5 Cyclic compression mechanical-electrical results (a) cyclic stress-strain curves; (b) current vs. cycle number for the 3:5 r-GO/PVA foam. 
Table S1 Chemical compositions for the GO, r-GO and r-GO/PVA composites analyzed by XPS with the nominal composition of untreated PVA

\begin{tabular}{lll}
\hline Sample Name & $\mathrm{C}$ at $\%$ & $\mathrm{O}$ at $\%$ \\
\hline GO & 68.5 & 31.5 \\
r-GO & 85.4 & 14.6 \\
r-GO:PVA 3:1 & 86.2 & 13.8 \\
r-GO:PVA 3:3 & 82.6 & 17.4 \\
r-GO:PVA 3:5 & 83.2 & 16.8 \\
r-PVA & 83.9 & 16.1 \\
PVA* & 66.7 & 33.3 \\
\hline
\end{tabular}

*For the untreated PVA the nominal composition $(66.7$ at \% C; 33.3 at \%O) was inserted, but the actual oxygen content may be higher due to residual carboxylic groups 